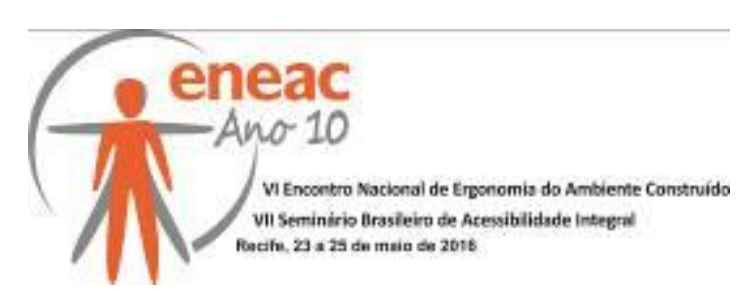

\title{
ANÁLISE ERGONÔMICA DO POSTO DE TRABALHO DO CONTROLADOR DE SISTEMA ELÉTRICO DA CELPE
}

\author{
ARAÚJO, Maiana Cunha (1); \\ ASSIS, Ana Tereza Santos (2); \\ MOURA, Isaura E. C. de L. e S. (3); \\ SOARES, Marcelo Marcio (4); \\ VILLAROUCO, Vilma (5). \\ (1) UFPE, Mestrado em Design \\ e-mail: maianacunha.ara@gmail.com \\ (2) UFPE, Especialização em Ergonomia \\ e-mail: tereza.arquitetura@gmail.com \\ (3) UFPE, Especialização em Medicina do Trabalho \\ e-mail: isauraupe@gmail.com \\ (4) UFPE, Pós-doutorado em Ergonomia \\ e-mail: soaresmm@gmail.com \\ (5) UFPE, Pós-doutorado em Engenharia e Gestão do Conhecimento \\ e-mail: villarouco@hotmail.com
}

\begin{abstract}
RESUMO
O presente trabalho consiste em uma análise ergonômica do posto de trabalho dos controladores de operações da CELPE e foi apresentado como trabalho de conclusão do curso de Especialização em Ergonomia da UFPE. Através de uma abordagem interdisciplinar, foram diagnosticados os problemas ergonômicos do ambiente de trabalho e propostas diretrizes de intervenção para que o ambiente se torne mais confortável, seguro e agradável para os operadores.
\end{abstract}

Palavras chave: ergonomia, avaliação ergonômica, salas de controle

\begin{abstract}
This work consists of an ergonomic analysis of the operation controllers workplace from CELPE and was presented as the conclusion work of the specialization course of Ergonomics in the Federal University of Pernambuco. Through an interdisciplinary approach, ergonomic problems were diagnosed in the workplace and guidelines for an intervention were proposed, so the environment can become more comfortable, safe and pleasant for the operators.
\end{abstract}

Keywords: ergonomics, ergonomics evaluation, control rooms 


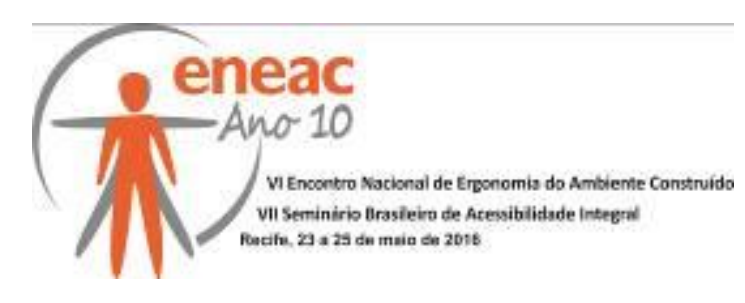

\section{INTRODUÇÃO}

Para lida (2005), a ergonomia tem por missão adaptar o trabalho ao homem através de aspectos físicos e organizacionais, desta forma, o trabalho não envolve apenas o homem e a máquina, mas também a organização que os envolve, os relacionamentos.

O objetivo do presente trabalho é realizar uma análise ergonômica do posto de trabalho dos controladores do sistema elétrico da CELPE, para alcançá-lo foram utilizados os seguintes passos: Primeiramente foi realizada uma pesquisa bibliográfica que levantou os aspectos relevantes e pertinentes em periódicos nacionais e internacionais, anais de congressos, dissertações de mestrado, teses de doutorado, normas técnicas e livros. Após isso foi escolhido o Método de avaliação mais pertinente, para a avaliação do ambiente de estudo, neste caso a Intervenção Ergonomizadora de Moraes e Mont'Alvão (2007), com o auxílio da Metodologia Ergonômica do Ambiente Construído (VILLAROUCO, 2001). De posse destes dados foram propostas, como resultado do projeto, recomendações e especificações de melhorias para a sala de controle.

\section{ERGONOMIA E SISTEMAS COMPLEXOS}

Um sistema pode ser definido como uma combinação de partes que, coordenadas, concorrem para certo fim (HOUAISS, 2009), e sua complexidade vem da natureza das ações que envolve. Um sistema é complexo quando seu funcionamento pode envolver situações potencialmente aleatórias e imprevisíveis, como pane elétrica, queda no abastecimento de água de refrigeração e até alteração nas condições ambientais (BOUYER; SZNELWAR, 2005). São sistemas com grande probabilidade de ocorrência de imprevistos, devido ao caráter de suas variáveis.

Os autores afirmam que a cada instante, durante sua atividade, o operador constrói o problema que ele deve resolver. Os mecanismos cognitivos que o indivíduo usa para compreender os fatos e gerir a situação de trabalho de modo a responder as exigências da tarefa e gerar os resultados esperados formam, com o decorrer dos anos, as suas competências.

A articulação entre a experiência, as habilidades e o conhecimento do operador que geram as competências, levando à conclusão de que as suas ações vão depender do repertório formado por essas três bases. Porém, para operar sistemas complexos, é necessário ainda o desenvolvimento de estratégias, que podem ser definidas, de acordo com Montmollin (1995), como um conjunto ordenado de passos que envolvem o raciocínio e a resolução de problemas, possibilitando a intervenção no sistema. As estratégias a serem adotadas nessa intervenção serão baseadas na interpretação das informações fornecidas pelo sistema, somando-se as competências mencionadas.

\subsection{Trabalho em Salas de Controle}

A automação de controle em atividades de processo contínuo surge em meio ao constante avanço tecnológico e a necessidade eminente de mordenização, o que tem alterado substancialmente as relações entre o usuário e os meios de produção. Os centros integrados de controle surgiram como uma possibilidade de agrupamento do controle de várias necessidades do processo produtivo em um só local (SANTOS, ZAMBERLAN e PAVARD, 2009), modernos sistemas de comunicação computadorizados tornam possível a busca por economia em larga escala, onde muitas vezes a máquina assume tarefas que na maioria dos casos antes eram realizadas pelos trabalhadores.

No trabalho em salas de controle, a carga de trabalho possui aspectos predominantemente cognitivos, assim, a intensidade do trabalho é um fator que deve sempre ser considerado, 


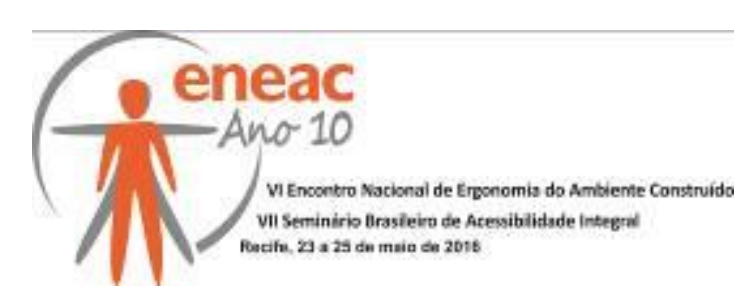

para que seja proporcionada a confiabilidade do sistema e seja reduzido o risco de acidentes. Para controlar um processo contínuo através do sistema automatizado, é necessário a utilização de saberes adquiridos pelos operadores através do tempo ao longo da carreira. O aspecto coletivo do controle de processos em ambientes dinâmicos e complexos também é marcado pela forte dependência do funcionamento e da interação entre as equipes e os diversos componentes do processo (ZAMBERLAN 1999). Dessa forma, a comunicação é imprescindível para que haja a interação e com esta a troca de informações necessária para manter o processo produtivo, que é complexo e marcado pela grande variabilidade de sistemas.

\subsection{Trabalho em Turnos}

A necessidade de trabalho em turno, em atividades que exigem atenção constante ao processo, é um fator de risco, uma vez que pode contribuir para alterações físicas e mentais dos operadores da sala de controle. Além das alterações físicas e biológicas causadas pela quebra do ritmo circadiano, as condições de trabalho em turnos de processo contínuo podem repercutir na vida social e familiar do trabalhador (SILVA, 2001).

A partir de dados de um levantamento do ano de 1994 da Fundação SEADE na área metropolitana de São Paulo, estima-se que $10 \%$ da população brasileira ativa trabalha em turnos ou a noite, porém segundo Fischer (2003), acredita-se que essa porcentagem seja maior, uma vez que o oferecimento de serviços disponíveis muitas horas por dia, durante os dias de semana e finais de semana vêm aumentando nos últimos anos.

No caso de o trabalho em turnos ser uma imposição da tecnologia de processamento contínuo, se faz necessário que seus efeitos negativos sejam minimizados desde a fase de concepção dos projetos de salas de controle, buscando sempre a qualidade das condições de trabalho e a segurança da operação.

No Brasil, a Constituição de 1988, determinou a redução das jornadas de trabalho em turnos initerruptos e de revezamento, com redução da jornada para 6 horas diárias ou negociação coletiva.

\section{METODOLOGIA}

Para o desenvolvimento desta pesquisa foram utilizados a Metodologia de Intervenção, desenvolvida por Moraes \& Mont'Alvão (2007) até a segunda etapa: Diagnose Ergonômica, pois este se trata de um trabalho onde foi apresentado o laudo ergonômico, e não se chegou a fase de projetação.

Para auxiliar o desenvolvimento da fase de Diagnose Ergonômica, foi aplicada a Metodologia Ergonômica do Ambiente Construído, MEAC (VILLAROUCO, 2008).

Como suporte para a aplicação das metodologia foram utilizadas ferramentas e instrumentos originários da ergonomia e de áreas interdisciplinares como psicologia ambiental e arquitetura.

\subsection{Instrumentos e Ferramentas}

- Observação assistemática- acontece de forma mais casual, sem um roteiro obrigatório a ser seguido, nesta não existem definições específicas. Geralmente consiste na primeira visita ao local analisado, onde ainda não foram definidos os aspectos relevantes a serem observados.

- Observação sistemática- possui um roteiro pré-definido, nela os pesquisadores sabem exatamente o que deve ser observado. Segundo Moraes e Mont'Alvão (2007) 


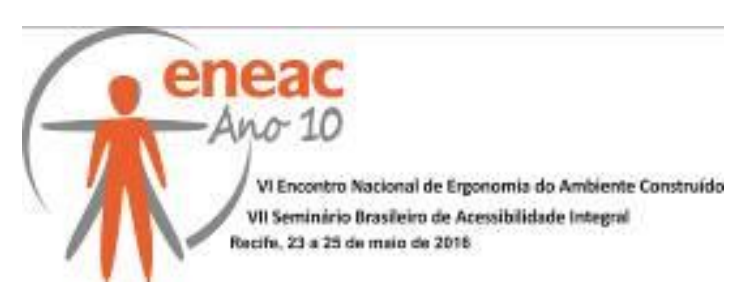

essa observação deve ser realizada na análise da tarefa, quando são realizados os registros comportamentais da tarefa.

- Análise Walkthrough - consiste em uma visita dos avaliadores a cada um dos ambientes de estudo, a qual é acompanhada por seus usuários (SANOFF, 1993);

- Entrevistas - são muito importantes para um trabalho de intervenção ergonomizadora, pois através desse instrumento é possível identificar a opinião do usuário para com a tarefa ou com o ambiente analisados. As entrevistas podem ser de vários tipos (SOARES, 2013);

- Questionários de auto-aplicação - é entregue ao pesquisado e este responde ao mesmo sozinho, sem a presença ou auxílio do pesquisador (SOARES, 2013);

- Constelação de Atributos -, idealizada por Moles em 1968 e aplicada por Schmidt (1974 apud VILLAROUCO; ANDRETTO, 2008), cuja construção do gráfico são utilizados procedimentos para avaliar a imagem simbólica do indivíduo frente ao ambiente e posteriormente, distinguir o que é objetivo do que é subjetivo na percepção do usuário;

- Mapa das Regiões Corporais - o objetivo da Escala de Desconforto Postural é mapear o desenvolvimento de desconforto percebido entre os pesquisados (CORLETT E BISHOP, 1976).

\section{ESTUDO DE CASO - ANÁLISE ERGONÔMICA DA SALA DE CONTROLE}

O estudo de caso foi realizado no COI - Centro de Operações Integradas da CELPE, com foco na análise das atividades e do ambiente de trabalho dos operadores I e II.

O Centro de Operações Integradas detém o Certificado de Qualidade ISO 9002 e foi construído para melhorar as condições de operação do sistema e de atendimento ao cliente, é responsável pelo controle do sistema elétrico (distribuição de energia elétrica para os usuários), o quadro de funcionários é composto por 1 gestor, 4 engenheiros, 14 controladores II e 55 controladores I ( dados de julho de 2014) destes, seis são mulheres e dois são deficientes físicos, trabalham num regime de plantão de oito horas com uma hora de descanço. O sistema operacional é o GSE oper.

\subsection{Atividades Desenvolvidas}

As atividades desenvolvidas no posto de trabalho da sala de controle do sistema elétrico da CELPE são realizadas em um sistema complexo, especializado que requer conhecimentos específicos. O objetivo da atividade é a prevenção de incidentes que possam interferir na operação do sistema elétrico ou recuperar o processo quando o incidente foi inevitável. Como se trata de uma atividade que exige atenção raciocínio lógico e concentração é passível de erro causados por fatores como fadiga, estresse ou falta de atenção.

Os operadores trabalham em conjunto com o callcenter e se comunicam com as equipes de campo (eletricistas) através de rádio, telefone e via Nastek que é um sistema operacional que envia mensagens de dados do GSE para o tablet das viaturas e vice versa.

\section{RESULTADOS DA ANÁLISE}

O objeto de trabalho compreendeu 20 postos de trabalho dos controladores de operações da CELPE o que consiste em três ilhas duas delas com oito postos de trabalho e uma com quatro. O sistema consiste em três subsistemas:

- Controlador de Operações 1 - responsável pelo gerenciamento de equipes. 


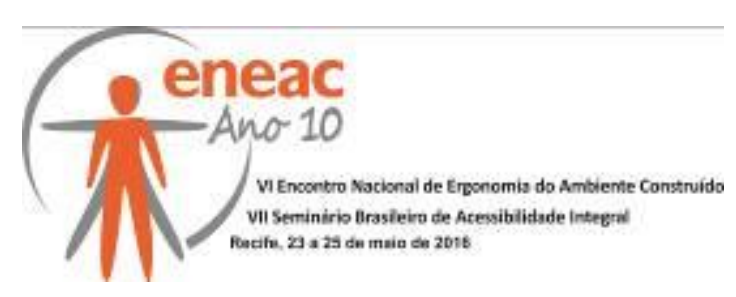

- Controlador de Operações 2 - responsável por manobras de grande porte.

- Supervisor - responsável pela supervisão e suporte dos operadores 1 e 2.

a) Priorização dos Problemas

A tabela GUT tem como principal objetivo definir a ordem de prioridade dos problemas que deverão ser atacados pelos gestores, a partir de três aspectos: gravidade, urgência e tendência. A tabela auxiliará os diretores da empresa a avaliar de forma quantitativa os problemas da empresa, tornando possível priorizar as ações corretivas e preventivas para solucioná-los (Tabela 1).

\section{Tabela 1 - Tabela GUT}

\begin{tabular}{|l|c|c|c|c|c|}
\hline \multicolumn{4}{|c|}{ Posto de trabalho do controlador I e II da CELPE } \\
\hline Problema & $\mathbf{G}$ & $\mathbf{U}$ & $\mathbf{T}$ & Produto & Média \\
\hline Sobrecarga de atividade & 5 & 5 & 5 & 125 & \\
\hline Excesso de entrada de dados & 5 & 5 & 5 & 125 \\
\hline Mesa não adaptável & 4 & 5 & 5 & 100 \\
\hline Rádios ruidosos & 4 & 5 & 4 & 80 \\
\hline Levantamento de partículas e poeira. & 3 & 4 & 5 & 60 \\
\hline Limpeza inadequada do carpete & 3 & 4 & 5 & 60 \\
\hline Não utilização do headset & 3 & 3 & 3 & 27 \\
\hline Turnos muito longos & 4 & 3 & 2 & 24 \\
\hline Toque de telefone incômodo & 2 & 4 & 2 & 16 \\
\hline Desconforto térmico & 3 & 3 & 1 & 9 \\
\hline Nível de iluminância está abaixo da média & 2 & 3 & 1 & 6 \\
\hline Zonas mal iluminadas & 2 & 3 & 1 & 6 \\
\hline Flexão do tronco & 2 & 1 & 2 & 4 \\
\hline Ruído da sala está acima da média & 2 & 2 & 1 & 4 \\
\hline Falta de local para guarda de pertences & 1 & 1 & 1 & 1 \\
\hline Impossibilidade de adaptação da iluminação & 1 & 1 & 1 & 1 \\
\hline Cadeiras com revestimento inadequado & 1 & 1 & 1 & 1 \\
\hline Não há acessibilidade para deficientes visuais & 1 & 1 & 1 & 1 \\
\cline { 1 - 4 }
\end{tabular}

A escala de priorização desses problemas serve como norteadora para a posterior diagnose, e através dela foi possível observar que os principais problemas a serem solucionados neste posto são relativos à sobrecarga cognitiva a que estão submetidos os trabalhadores.

\subsection{Resultados da Aplicação da MEAC}

Análise Global do Ambiente - nessa fase procurou-se obter o maior número de informações possíveis do ambiente através de observações sistemáticas, aplicação de questionários e entrevistas com operadores e a gerência.

O acesso ao edifício é feito pela portaria, para tal é necessário a identificação. Para acessar a sala de controle é necessário avisar previamente ao supervisor e solicitar permissão para entrada, onde existe uma senha de acesso. Foi observado que a sala é bastante escura, o que pode causar fadiga. Também, devido ao uso de carpete, existe um cheiro não muito forte de mofo. O ambiente é silencioso, e devido à atividade desempenhada ou ao layout, não existem muitas conversas ou interação entre os operadores. 


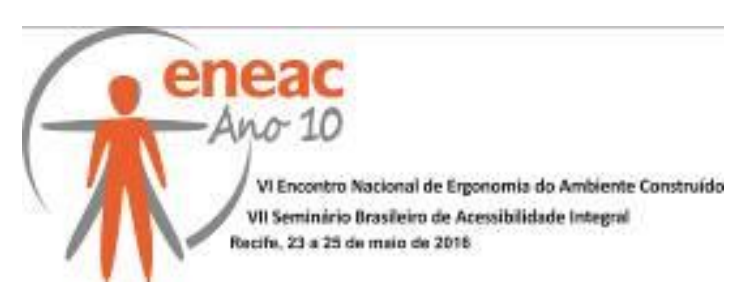

Figura 1 - Foto Panorâmica

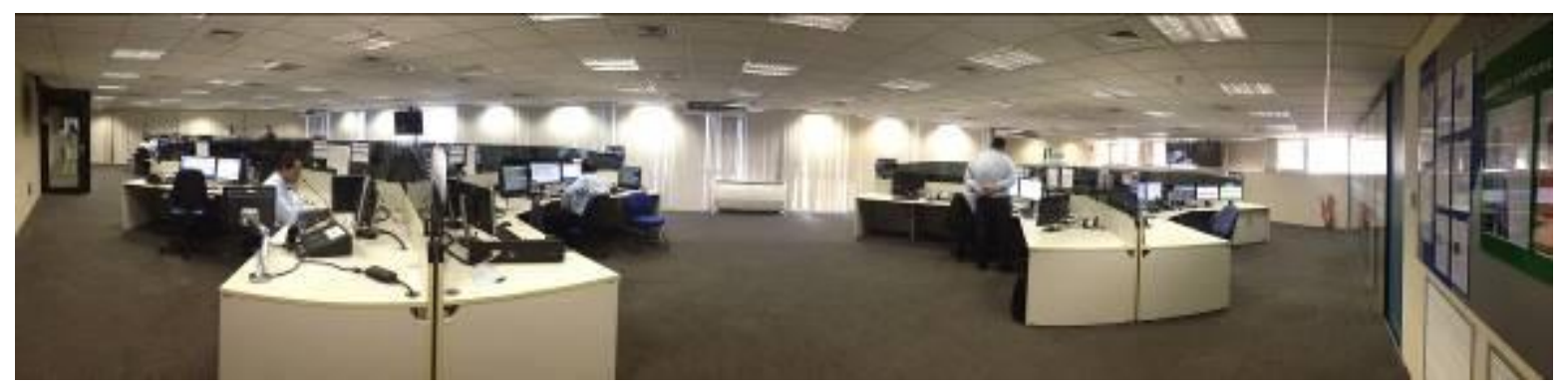

Fonte: Autoras

Identificação da Configuração Ambiental - Esta etapa da metodologia trata do levantamento de todos os dados relativos ao ambiente físico, tais como dimensões do espaço, índices de conforto ambiental (iluminação, ventilação, ruído, temperatura), fluxos e deslocamentos, layout, materiais de revestimento e condições de acessibilidade. Tais investigações levam às primeiras hipóteses sobre a interferência do ambiente no trabalho.

Figura 2 - Planta baixa da sala de controle

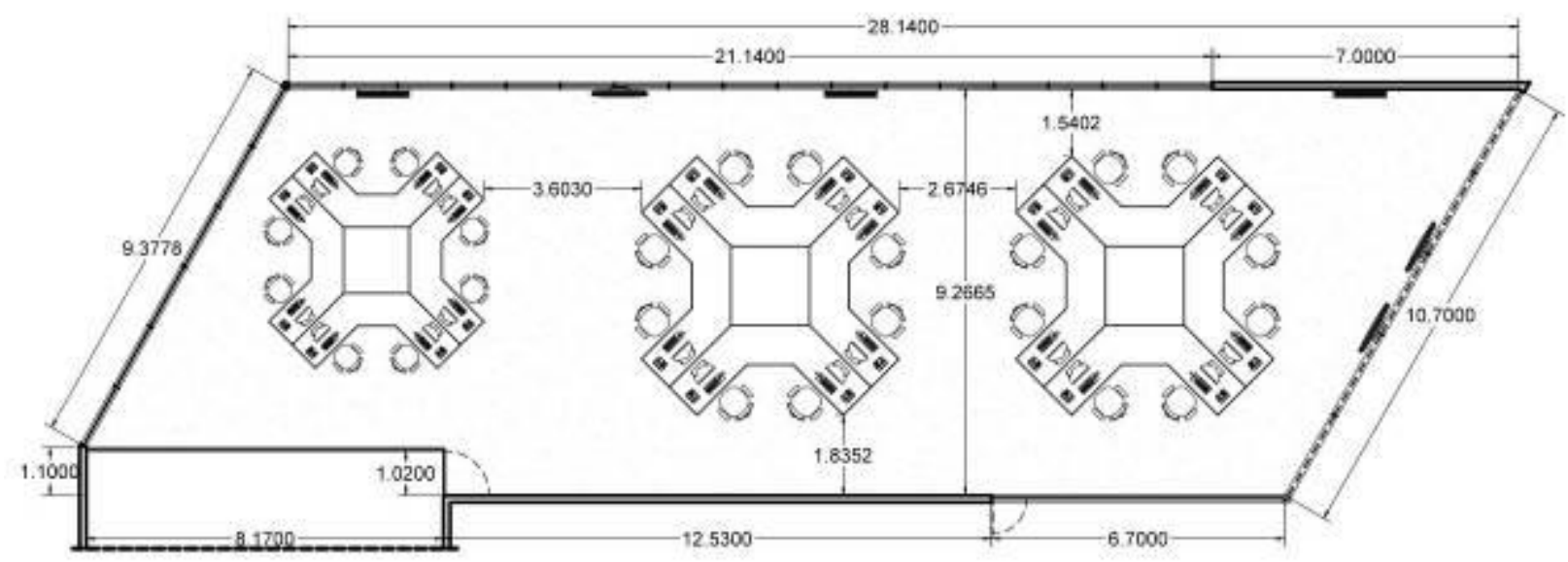

Fonte: Autoras

Conforto Acústico - foi utilizado como referência a NBR 10152 que fixa as condições exigíveis para avaliação da aceitabilidade do ruído ambiente. Os valores encontrados foram decrescentes de acordo com o turno de medição a começar pela manhã. A média da manhã foi $65.83 \mathrm{~dB}(\mathrm{~A})$, a tarde $61.45 \mathrm{~dB}(\mathrm{~A})$ e a noite $59.43 \mathrm{~dB}(\mathrm{~A})$. Isso mostra que os níveis de ruído estão sempre acima do aconselhado pela norma.

Conforto Térmico - A NR 17, considera que nos locais de trabalho onde são executadas atividades que exijam solicitação intelectual e atenção constantes, tais como: salas de controle, laboratórios, escritórios, salas de desenvolvimento ou análise de projetos, dentre outros, é recomendado um índice de temperatura efetiva entre $20^{\circ} \mathrm{C}$ (vinte) e $23^{\circ} \mathrm{C}$ (vinte e três graus centígrados) e velocidade do ar não superior a $0,75 \mathrm{~m} / \mathrm{s}$. Considerando o conforto como um termo muito relativo e diretamente relacionado com a cultura e vivência de cada indivíduo é difícil afirmar que uma temperatura de $20^{\circ}$ seja confortável para quem está acostumado a viver no no clima tropical do nordeste brasileiro. Um estudo de Hetzberg afirmou ser o conforto a "ausência de desconforto" (Lueder, 1983). Com isso, para a análise 


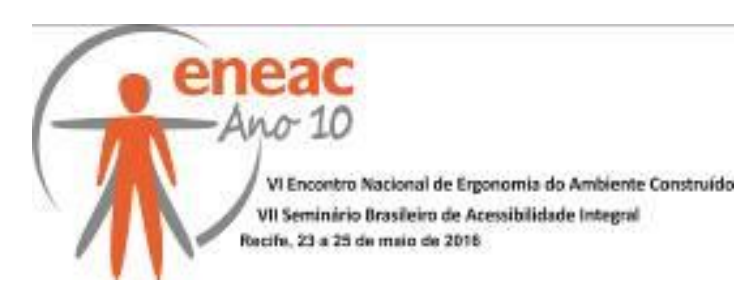

do conforto térmico deste trabalho foram utilizados como referência os dados fornecidos por Ruskin Freitas que considera o clima tropical quente e úmido do Recife.

As temperaturas encontradas na sala de controle se encontram entre $24^{\circ}$ e $26^{\circ} \mathrm{C}$ (vinte e quatro e vinte e seis graus celsius), o que seria considerado desconfortável de acordo com a NR17, porém é considerado "confortável" para o clima do Recife.

Conforto Lumínico - A NR 17 afirma que os níveis mínimos de iluminamento a serem observados nos locais de trabalho são os valores de iluminâncias estabelecidos na NBR 5413, norma brasileira registrada no INMETRO. A medição dos níveis de iluminamento foram executadas de acordo com a norma, no campo de trabalho onde se realiza a tarefa visual, utilizando-se de luxímetro com fotocélula corrigida para a sensibilidade do olho humano e em função do ângulo de incidência. No caso de não definido o campo de trabalho, este foi um plano horizontal a $0,75 \mathrm{~m}$ (setenta e cinco centímetros) do piso.

Em nenhum horário os níveis de iluminância encontrados estão de acordo com o estabelecido pela norma. Observa-se que poucos pontos isolados alcançam o valor de 500 lux, mas isso consiste em casos isolados. Uma possível causa para agravar esse valor pode ser a cor do carpete que é muito escuro.

Acessibilidade e Arranjo Físico | Layout - O termo acessibilidade aqui citado refere-se à total capacidade de o usuário utilizar o ambiente com autonomia, desde o acesso ao edifício até o seu posto de trabalho. Existe uma parada de ônibus em frente ao edifício, e este está localizado em uma área central da cidade, onde passam várias linhas de ônibus. As calçadas são conservadas, porém revestidas com a tradicional pedra portuguesa, que às vezes dificulta o passeio com cadeiras de rodas. Para ter acesso à portaria o visitante precisa subir uma grande escadaria, porém existe o acesso através de elevador para quem entra pelo estacionamento. Todos os espaços são amplos e o layout possibilita a circulação de maneira adequada e com segurança. A sinalização está adequada e é possível encontrar os ambientes através da mesma.

Postos de trabalho - Os postos de trabalho estão dispostos em 3 células e cada uma delas possui capacidade para oito trabalhadores. No centro de cada célula encontra-se o espaço destinado aos servidores, equipamentos responsáveis pelo funcionamento do sistema. De acordo com a NBR 9050, as dimensões da mesa estão de acordo com o necessário para uma atividade sem necessidade de grande precisão e executada por tempo prolongado.

Cada controlador precisa administrar 3 fontes distintas de informação: rádio, telefone e sistema. Cada uma dessas fontes requer uma administração particular de suas informações, pois o telefone concentra mais de 100 linhas diferentes, que permitem ao profissional entrar em contato com os diversos setores envolvidos nas atividades, e o uso do sistema envolve a administração de informações advindas de 2 a 5 telas de computador, dependendo do cargo (controlador 1 ou 2).

As cadeiras são reclináveis e possuem apoio para as costas mais alto, além de serem acolchoadas e ajustáveis. Porém alguns funcionários se queixam do material do revestimento, que aquece facilmente causando desconforto térmico. As mesas não são ajustáveis, o que faz com que alguns funcionários, de maior estatura, sintam-se desconfortáveis.

Revestimentos - o revestimento em carpete é adequado, visto que diminui consideravelmente o ruído oriundo do deslocamento dos profissionais no ambiente. No entanto, o carpete é um revestimento que demanda limpeza rigorosa e periódica, que só é feita eficientemente através do uso de equipamentos adequados (como aspiradores de pó). Por ser um ambiente que nunca é desocupado (devido aos turnos contínuos), e pelo fato de tais equipamentos de limpeza serem naturalmente ruidosos, a limpeza desse material não pode ser feita adequadamente, gerando desconforto nos usuários. 


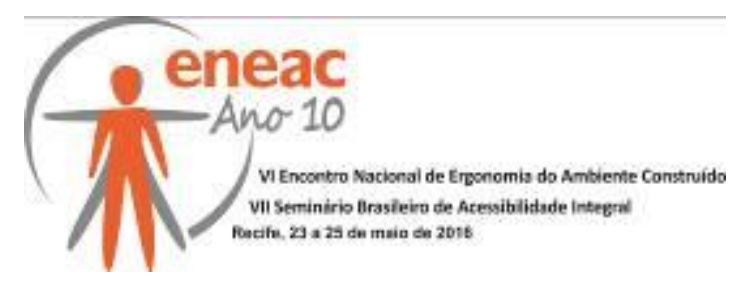

As paredes são constituídas de materiais diversos, pois parte da sala é vedada com alvenaria comum, revestida com massa e pintada com tinta de acabamento opaco, e outra parte é vedada por esquadrias que vão do piso ao teto, que possuem estrutura em alumínio e fechamento em vidro transparente sem película, e cujo controle da luz natural é obtido por meio da utilização de cortinas tipo venezianas na cor branca. Considerou-se que nenhum dos revestimentos causa desconforto visual oriundo do uso de materiais reflexivos, pois mesmo o vidro passa todo o tempo coberto pelas persianas, ou desconforto pelo uso de cores que causam incômodo aos usuários. O material utilizado na persiana, e mesmo o tipo de vedação, foi considerado inadequado. A persiana consiste numa superfície retangular de material plástico opaco, que distribui-se intermitentemente ao longo da esquadria, criando várias brechas de luz natural que causam desequilíbrio na uniformidade da iluminação. Essas brechas permitem que apenas fachos de luz natural entrem no ambiente, podendo causar fadiga visual nos postos de trabalho onde o operador passa o turno diurno inteiro de frente para essa superfície.

O teto da sala é composto de material acartonado que favorece a acústica da sala por absorver o ruído e diminuir sua reflexão no ambiente. A cor branca e opaca também não causa reflexividade acentuada da luz. Destaca-se também a eficiência da iluminação, pois as luminárias utilizadas possuem pequenos jogos de espelhos que favorecem a distribuição uniforme da luz, tornando-a difusa e evitando pontos de iluminação mais fortes e mais fracas, além de ter uma distribuição pontual e uniforme ao longo da sala. O problema na iluminação reside na grande quantidade de lâmpadas que não funcionam, provocando diferenças grandes de iluminação em determinados pontos da sala, além de estarem todas ligadas no mesmo circuito, o que impede que os operadores mantenham acesas somente as áreas da sala em uso naquele turno.

Análise do Ambiente em Uso - esta etapa visa identificar o quanto facilitador ou inibidor o ambiente representa ao desenvolvimento das atividades que abriga. É realizada uma análise do desempenho das atividades no ambiente, identificando como o espaço é usado através da observação direta.

A observação permitiu à equipe visualizar o incômodo causado pela luz natural naqueles trabalhadores cujos postos de trabalho localizam-se na posição oposta às esquadrias da fachada. Outro fator importante foi durante o uso dos equipamentos, que fazem com que os controladores assumam posturas inadequadas para atender o telefone, por exemplo, e continuar com as duas mãos livres. Os controladores não estabelecem muito contato verbal entre si, mas mantêm comunicação constante através dos telefones, rádios e computador, de modo que a natureza da tarefa demanda silêncio e concentração, e sob esse aspecto a equipe observou que o ruído dos equipamentos pode estar interferindo negativamente no trabalho.

No mais, o ambiente é claro, amplo, permite boa circulação e possui temperatura confortável. A observação mais aprofundada das questões incômodas ao trabalhador foram abordadas na etapa seguinte da metodologia, que consiste na análise da percepção do usuário.

Análise da Percepção do Usuário - Através da aplicação de questionários, a equipe pôde traçar o perfil dos operadores e obter informações acerca da sua percepção do posto de trabalho que ocupam. Para tanto, conseguimos que 38 operadores se disponibilizassem para participar da pesquisa, o que representa estatisticamente uma amostra com nível de confiabilidade dos resultados de $95 \%$ e erro amostral de $10 \%$ (SANTOS, 2014).

Parte das informações obtidas através dos questionários foram relativas a opiniões gerais dos usuários sobre a infraestrutura da empresa. Esta etapa consistiu na utilização de uma escala onde o 1 significa "muito ruim" e 5 significa "muito bom". 


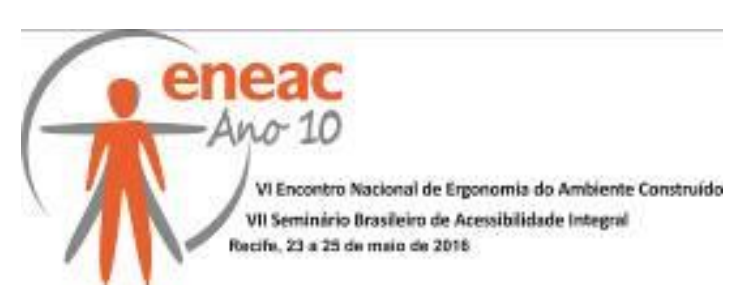

O item melhor avaliado nessa escala foi referente ao tamanho da sala, seguido pelo isolamento contra ruídos internos. As questões relativas ao ambiente propriamente dito, em geral, foram bem avaliadas. A sala possui dimensões adequadas para o conforto dos usuários, e a questão acústica pôde ser observada na análise dos revestimentos, que mostrou a utilização de materiais no piso e no teto que diminuem a reflexão do som.

$\mathrm{O}$ item avaliado mais negativamente foi referente ao número de vagas no estacionamento, que não é suficiente para todos os funcionários e também não existem vagas exclusivas para controladores. Dependendo do turno, o funcionário que precisar estacionar fora das dependências da empresa tarde da noite ou muito cedo durante a manhã pode acabar em situação de insegurança. O segundo item avaliado mais negativamente foi referente à qualidade do ar (odores e poeira). Como observado no item "Revestimentos" da etapa de Identificação da Configuração Ambiental, o carpete da sala não pode ser limpo adequadamente, devido à natureza da atividade na sala, que impede a utilização de aparelhos mais adequados para a limpeza, e esta condição está refletida no resultado desta etapa da pesquisa.

\section{Resultado da Aplicação da Constelação de Atributos}

A aplicação da constelação mostrou que os operadores estão satisfeitos com relação aos equipamentos, pois o item mais mencionado foi o que diz que a sala é bem equipada. Em seguida percebe-se que a questão da poeira aparece novamente, tendo aparecido antes na investigação das opiniões gerais como o segundo item avaliado mais negativamente, e agora aparece como o segundo item mais citado pelos operadores. "Muito stress" é o terceiro item na sequência de importância para os usuários, e decorre da alta demanda cognitiva inerente à atividade.

Figura 3 - Constelação de Atributos: Ambiente Real

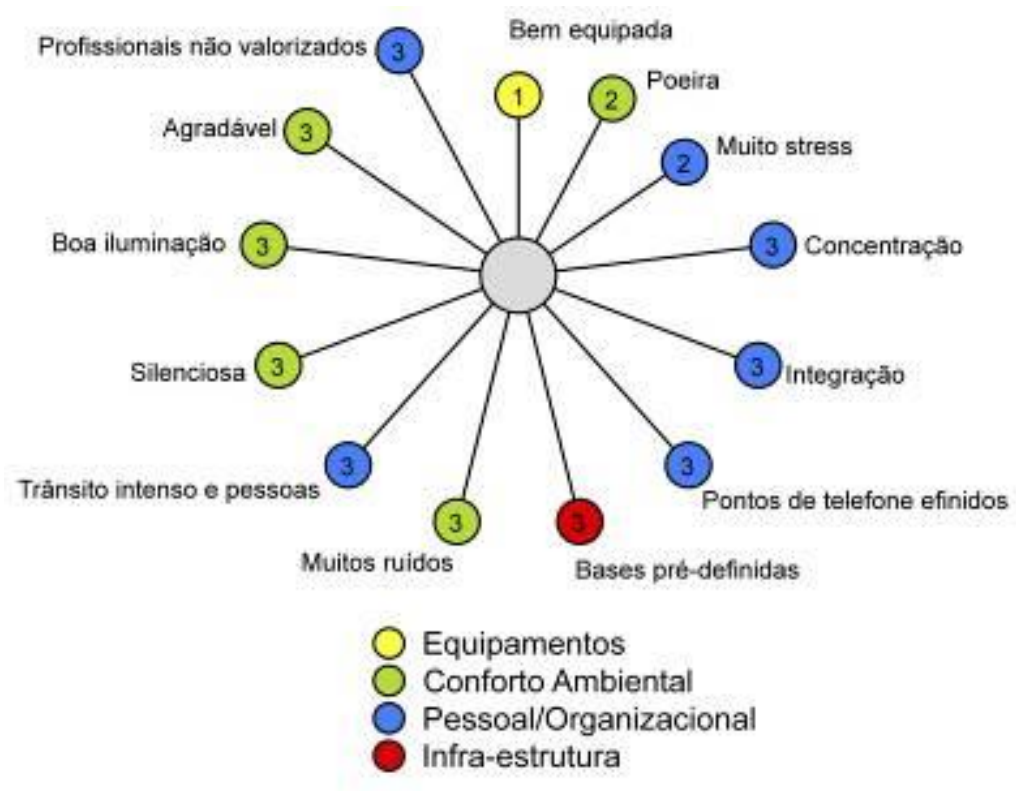

Fonte: Autoras

\section{RECOMENDAÇÕES ERGONÔMICAS}

Dentro da categoria de problemas interfaciais, destacou-se a dificuldade sofrida pelos operadores para conciliar as diferentes fontes de informação durante a realização das tarefas, além dos movimentos de rotação do tronco provocados pela disposição dos vários 


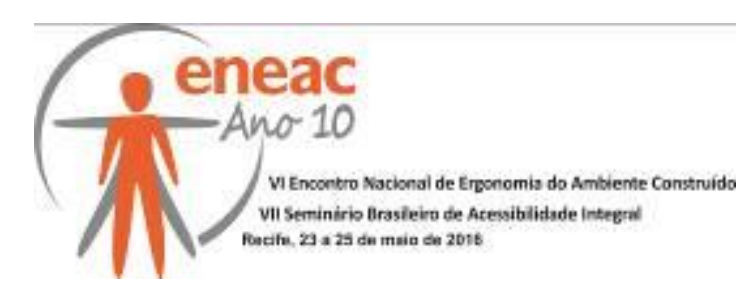

monitores e posturas inadequadas pela não utilização do equipamento de headset. As soluções para essas questões envolvem principalmente a interferência nos equipamentos utilizados pelos operadores, como a unificação do sistema, visando a diminuição do número de fontes de informação, a substituição dos vários monitores por um único equipamento e o incentivo à utilização do headset.

Os problemas relacionados à questão organizacional são causados pela longa duração do turno, pois a natureza da atividade envolve grande comprometimento da atenção do operador,o que provoca fadiga. Por ser um trabalho que exige capacidade analítica e decisória, e não haver a possibilidade de criar mais intervalos ao longo do turno, recomenda-se a diminuição do turno de oito para seis horas.

Outros pontos importantes avaliados encontram-se na esfera comunicacional, onde identificou-se que o som emitido pelos telefones e rádios provocam grande incômodo sonoro, além da grande quantidade de informações a serem administradas por cada trabalhador. As recomendações da equipe consistem em substituir os equipamentos para que ajam mais sinais luminosos que sonoros, e a unificação do sistema, para que seja mais fácil administrar as diversas informações.

A questão da infraestrutura foi bem avaliada pela equipe, porém a falta de um local próximo ao posto de trabalho para guardar os pertences pessoais dos funcionários causa desconforto aos mesmos. Existem armários para essa finalidade, porém localizam-se na copa. A sugestão da equipe é que haja uma modificação do mobiliário das mesas para que haja pelo menos uma gaveta disponível para o funcionário utilizar em seu turno, o que traria maior conforto para o usuário.

Sobre as questões físicas e ambientais da sala, a primeira crítica feita pela equipe entra em acordo com observações negativas feitas pelos trabalhadores acerca do material utilizado no piso da sala. Acusticamente eficiente, o carpete favorece a diminuição do ruído do deslocamento na sala, porém não pode ser eficientemente limpo, o que nos leva ao problema classificado como biológico, pois a existência de ácaros e poeira leva ao surgimento de inúmeras reações alérgicas.

Por ser um ambiente que funciona $24 \mathrm{~h}$ por dia, durante os 7 dias da semana, a sala não pode ser limpa com equipamento de aspiração adequado, pois o ruído produzido interferiria na concentração da equipe. A solução encontrada foi a substituição do carpete por piso vinílico em rolo (menor número de emendas) com material tratado para melhor desempenho acústico. Esse tipo de material é produzido por vários fabricantes nacionais, tem fácil aplicação e a limpeza é muito mais simples e eficiente.

Depois de realizadas as medições observou-se também que o nível de ruído no ambiente é maior do que o recomendado pela NBR 10152, e a pesquisa com os usuários revelou que muitos apontam como principal fonte de ruído o rádio utilizado por eles, seguido pelo telefone e equipamentos condicionadores de ar. Como já mencionado, a solução para o rádio e telefone está na substituição dos equipamentos por um que integre os sistemas, e que use mais sinais luminosos que sonoros.

O nível de iluminância está abaixo do recomendado pela NBR 5413, e isso pode estar sendo ocasionado pela não substituição de lâmpadas queimadas nas luminárias. A solução consiste numa manutenção mais efetiva dos equipamentos da sala, e substituição do que não funciona mais. Aliada a esta questão da iluminação também se observa que as luminárias da sala estão interligadas no mesmo circuito, de modo que nos turnos noturnos não é possível apagar as luzes das áreas onde não ajam trabalhadores. Uma solução que pode proporcionar economia de energia seria dividir as luminárias em três circuitos distintos, de modo que fiquem dispostas sobre cada célula de trabalho. 


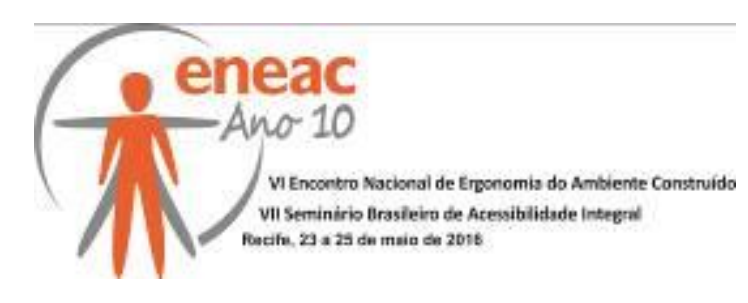

Alguns trabalhadores mais altos queixaram-se da altura das bancadas de trabalho. Os mais baixos podem utilizar o ajuste das cadeiras e apoio ergonômico para os pés, mas os mais altos não possuem meios de se acomodar adequadamente. Como previsto pela NR-17, é obrigatória a substituição do mobiliário por mesas ajustáveis, e assim adequar o posto de trabalho aos trabalhadores.

Também na categoria mobiliário, muitos funcionários queixam-se do material que reveste as cadeiras, acusando um desconforto proveniente do calor provocado por ele. Sugere-se a substituição desse mobiliário por cadeiras com revestimento têxtil em tela, pois esse material vazado permite a passagem do ar e portanto diminuirá a sensação de desconforto térmico.

Em matéria de acessibilidade, a sala tem dimensões adequadas, de acordo com a NBR 9050, e o acesso a ela também é viabilizado pela existência de rampas e elevadores. Porém, um deficiente visual não tem acesso a informações tanto no percurso para acesso à sala, quanto na sala em si. Não há deficientes visuais trabalhando nesse posto de trabalho, mas se algum precisar chegar à sala, não encontrará sinalização tátil no caminho. A sugestão da equipe é a implantação de sinalização tátil, tanto no acesso a este quanto a outros departamentos da empresa.

Ainda sobre a questão físico ambiental, a disposição das esquadrias na sala também é um fator preocupante. Duas das quatro paredes da sala são completamente compostas por esquadrias, do piso ao teto, e uma dessas paredes é a fachada do edifício, voltada para o poente. As esquadrias são vedadas por persianas, mas elas não impedem que o sol poente ofusque os trabalhadores. A solução proposta pela equipe é o revestimento dos vidros com película adesiva escura, reduzindo a intensidade e o ofuscamento provocado pela luz externa.

\section{CONCLUSÕES}

A importância do ambiente de trabalho para a execução das atividades foi por muito tempo negligenciada, porém, felizmente, nos últimos anos estudos voltados para a questão da ergonomia têm influenciado na vida dos trabalhadores e nos postos de trabalho. No caso em estudo, um ambiente de sala de controle, é fundamental o olhar do ergonomista, pois existe uma grande demanda cognitiva e em menor grau uma demanda física, porém, qualquer tipo de desconforto pode influenciar negativamente os resultados ali buscados.

Com isso é de fundamental importância a concepção de projetos específicos para esse tipo de ambiente, tendo em vista essa necessidade foi criada uma norma específica para este fim, a ISO 11064 - The Ergonomic Design of Control Center. A partir do uso desta norma e de outras referências normativas a equipe considera que alcançou o objetivo deste trabalho, uma análise ergonômica do posto de trabalho dos controladores elétricos da CELPE.

A natureza complexa do trabalho do controlador do sistema elétrico da CELPE nos levou a refletir acerca de como um trabalho de alta demanda cognitiva pode interferir no bem estar dos funcionários, e como a ausência de conforto, mesmo que em pequenas proporções, pode interferir na qualidade desse trabalho. A valorização do profissional consiste não somente em atender suas necessidades básicas, mas em compreender e suprir suas necessidades específicas, pois a qualidade de vida no trabalho começa com sua adaptação a quem o exerce.

\section{REFERÊNCIAS BIBLIOGRÁFICAS}

CORLETT E. N.; BISHOP, R. P. A technique for assessing postural discomfort ergonomics, n.19; 175-182, 1976. 


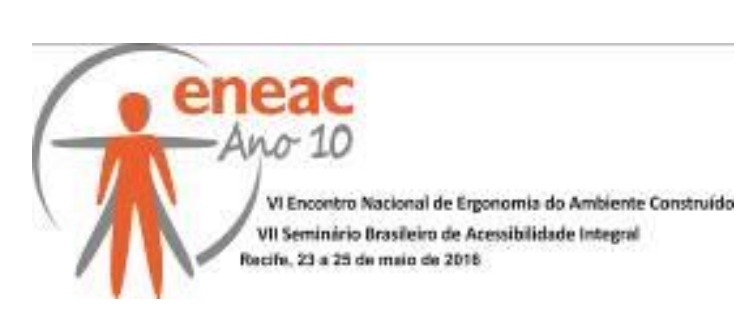

BOUYER, G.C.; SZNELWAR, L.I. Análise cognitiva do processo de trabalho em Sistemas Complexos de Operações. Ciências\&Cognição, v.4, p.02-24, 2005.

FISCHER, Gustave-N. Psicologia Social do Ambiente. Lisboa: Instituto Piaget, 1994.

HOUAISS. Dicionário eletrônico Houaiss da língua portuguesa. Rio de Janeiro: Objetiva, 2009.

IIDA, Itiro. Ergonomia: projeto e produção. 2. ed. São Paulo: Edgard Blücher, 2005.

MONTMOLLIN, M.. “Complexité”. In: Montmollin, M. (eds.), Vocabulaire de L’Ergonomie, Toulouse, França, Octares Editions, 1995.

MORAES, Anamaria de; MONT'ALVÃO,Cláudia. Ergonomia: conceitos e aplicações. 3. ed. Rio de Janeiro : Creatio Design e Comunicação Ltda / Escritório Modelo de design da PUC - Rio / Gráfica Gol, 2007.

SANOFF, H. School building assessment methods. 2001. Disponível em < http://www.edfacilities.org/pubs/sanoffassess.pdf >. Acesso em 30 jul. 2013.

SANTOS, V; ZAMBERLAM, M. C. Projeto Ergonômico de Salas de Controle. São Paulo: Fundación Mapfre, 1992.

SILVA, L. B. da. Análise da relação entre produtividade e conforto térmico: o caso dos digitadores do centro de processamento de dados e cobrança da Caixa Econômica Federal do estado de Pernambuco. Dissertação (Mestrado em Engenharia de Produção). Universidade Federal de Santa Catarina. Florianópolis, 2001.

SANTOS, Glauber Eduardo de Oliveira. Cálculo amostral: calculadora on-line. Disponível em: <http://www.calculoamostral.vai.la>. Acesso em: [02/2014].

SOARES, Marcelo M. Técnicas e ferramentas para a intervenção ergonomizadora. Apostila do 80 curso de especialização em ergonomia. Recife: UFPE, 2013.

VILLAROUCO, V. Modelo de avaliação de projetos. Tese (Doutorado em Engenharia de Produção). Universidade Federal de Santa Catarina. Florianópolis, 2001.

VILLAROUCO, V.; ANDRETO, Luiz. F. M. Avaliando desempenho de espaços de trabalho sob o enfoque da ergonomia do ambiente construído. Produção, v. 18, n. 3, p. 523-539, 2008

ZAMBERLAM, M. C. P. L. A Perspectiva Ergonômica no Projeto de Salas de Controle na Indústria de Processo Contínuo. Tese (Doutorado). Engenharia de Produção. COPPE/UFRJ, 1999. 